\title{
Pin-site scar revision with subcisions and acellular dermal matrix
}

\author{
Yu Jin Kim, Ji Hun Kim, \\ Yun Sang Kim, Young Woo Cheon \\ Department of Plastic and Reconstructive \\ Surgery, Gil Medical Center, Gachon \\ University College of Medicine, Incheon, \\ Korea
}

External fixation is widely used in orthopedic and reconstructive surgery. However, it may leave retracted and depressed scars because it involves the percutaneous placement of transosseous pins or wires that are secured to an external scaffolding. These scars do not resolve or improve spontaneously, causing patients to experience dissatisfaction and possibly requiring a surgical intervention. Moreover, the management of scars that arise from external fixator pin sites is challenging because of their fibrotic and depressive features. However, by using subcisions and inserting acellular dermal matrix under the scars, the contour of the scars can be improved easily. Therefore, we present a case of pin-site scar revision using a technique that we developed.

Keywords Cicatrix / External fixator / Acellular dermis

\section{INTRODUCTION}

Applying external fixators or distractors is a common method used to manage complex fractures [1]. Although good alignment and bony union are important, prolonged pin placement may cause epidermal ingrowth and tethering of soft tissues to the underlying bone [2]. These can result in retracted and depressed scars in the site where the pins passed through the skin, and these scars do not resolve or improve spontaneously [1-5]. Several methods have been introduced to manage these scars [3-5]. A surgical method combining W-plasty and a buried dermal island was introduced in $1994[4,6]$. Subsequently, a procedure involving blind dissection under the scar tissue using sharp scissors with a $1-\mathrm{cm}$ longitudinal incision was introduced [5]. In another study, it was found to be possible to improve the appearance of a pin-site scar by performing subcisions with a 16-gauge needle and fat injections [3]. However,

Received: Oct 8, 2019 Revised: Oct 21, 2019 Accepted: Oct 28, 2019 Correspondence: Yu Jin Kim Department of Plastic and Reconstructive Surgery, Gil Medical Center, Gachon University College of Medicine, 21 Namdong-daero 774beon-gil, Namdong-gu, Incheon 21565, Korea Tel: +82-32-460-2770, Fax: +82-32-461-2774,

E-mail: pseugene@gilhospital.com

Copyright @ 2020 The Korean Society for Aesthetic Plastic Surgery.

This is an Open Access article distributed under the terms of the Creative Commons Attribution Non-Commercial License (https://creativecommons.org/licenses/by-nc/4.0/) which permits unrestricted non-commercial use, distribution, and reproduction in any medium, provided the original work is properly cited. $\quad w w w . e-a a p s . o r g$ if these methods do not resolve a scar, it may be necessary to try another method.

Acellular dermal matrix (ADM) has been used for soft tissue replacement in skin grafts, facial augmentations, and other reconstruction procedures $[7,8]$. The implantation of ADM can enable much of the original augmented volume to be retained over time, making it useful for volume replacement procedures [7-9]. Therefore, we describe a case of pin-site scars that resolved after use of an effective method based on ADM implantation and subcisions.

\section{CASE REPORT}

An 18-year-old Asian woman presented with multiple dimpled scars on her left thigh. She had a distal femur fracture on the left side at the age of 6 years and underwent external fixation at that time. She had eight scars along the vastus lateralis muscle, each of which was $1 \mathrm{~cm}$ in size. With a depression of $0.5 \mathrm{~cm}$ in the standing position, the scars worsened when her knee was bent. Although we performed an autograft fat injection at the sites of the scars, the scars remained depressed (Fig. 1). Therefore, 6 months after the first operation with a fat injection, we planned to use an ADM to supplement the soft tissue and to enhance the dermal layer. The incisions were made in the center of the scarred region (with four consecutive scars on each side), providing easy access to the surrounding tissues and leaving no additional scars. The use of zig-zag incisions enabled a wider field of view to be used, and the resultant scar was less noticeable than the linear scars after the operation 

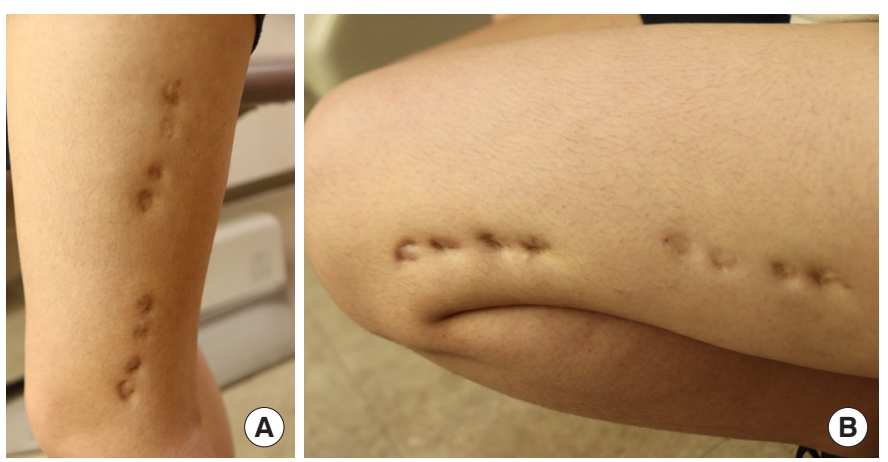

Fig. 1. (A) Eight dimpled scars measuring approximately $1 \mathrm{~cm}$ were present along the vastus lateralis muscle of the left thigh. They were not improved by an autologous fat graft. (B) In the position of knee flexion, the depression of the scars was aggravated.

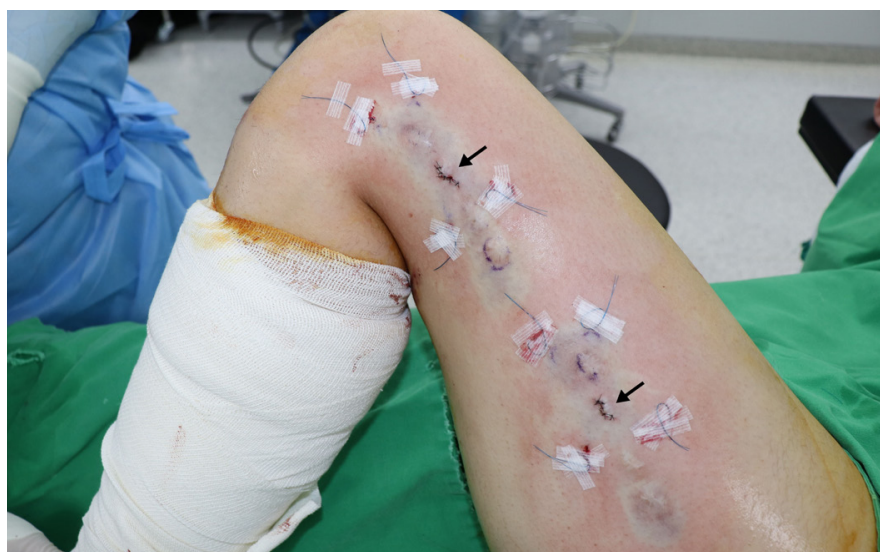

Fig. 2. An intraoperative photo of the patient. Two incisions were made (black arrows) and after enough subcisions were made, an acellular dermal matrix (ADM) measuring $1 \times 4 \times 0.1 \mathrm{~cm}$ was inserted into each incision. Each ADM was fixed by pull-out sutures and wound closure tape was applied.

(Fig. 2). Blunt subcutaneous undermining was performed with Metzenbaum scissors to break up the fibrous bands that caused the depressions. Subcutaneous dissection was extended step-by-step under close observation to avoid injuring the dermal layers. Sufficient elevation of the scars was done gradually and a freely movable flap was visually confirmed. With sufficient dissection, two ADMs measuring $1 \times 4 \times 0.1 \mathrm{~cm}$ (AlloDerm; LifeCell Corp., Branchburg, NJ, USA) were inserted through each incision. Using Prolene \#3-0, pullout stitches without knots were used to locate each ADM under the skin flap, and wound closure tape (Steri-Strip; 3M, Maplewood, MN, USA) was applied to the skin to stabilize the ADMs (Fig. 2). The pullout threads were removed on postoperative day 7 , and the stitches were removed from the incision site on postoperative day 13. Prior depressions caused by bending of the knee could not be observed in any positions taken by the patient (Fig. 3). One month after the operation, treatment with an Erbium glass fiber la-
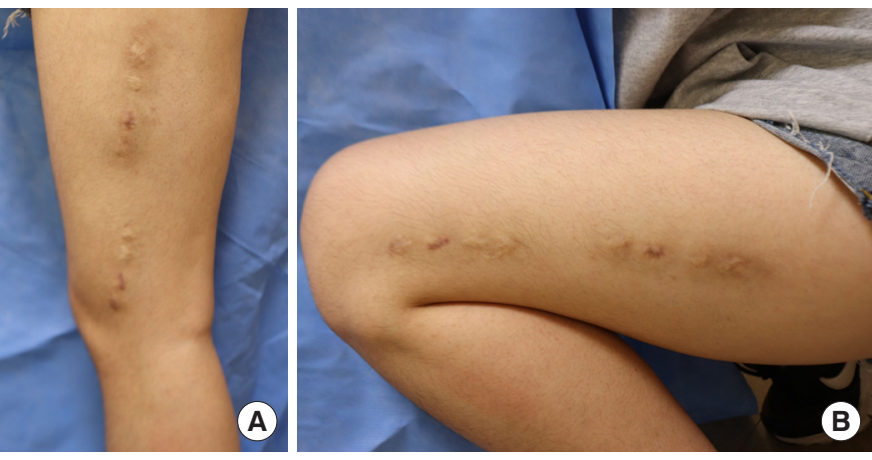

Fig. 3. (A) Clinical photograph at 4 months postoperatively. The dimpled scars had improved. (B) After the operation, the scars were not aggravated, and they remained intact in the position of knee flexion.

ser (MOSAIC HP; Lutronic, Goyang, Korea) was administered to improve the scars.

\section{DISCUSSION}

Although scar formation is an inevitable consequence of wound healing, it can have a significant impact on patients physical and psychological well-being [10]. The ideal scar is directed along a relaxed skin tension line, is thin and flat, and matches well with the surrounding skin [6]. In clinical practice, many scars are symptomatic, unsightly, and not ideally oriented with the skin $[6,11]$. Especially in scars resulting from external fixation, prolonged pin placement can cause skin pressure or pin tract infections, leading to fibrotic and depressed scars on the pin-fixed site [3-5].

To manage scars induced by external fixation, adequate undermining of the soft tissues and volume replacement are needed. It is important to perform enough subcisions of the adhesions and fibrotic tissues under the scar because scars resulting from the percutaneous placement of transosseous pins or wires are hard to release $[1,3]$.

In our case, we thought that scar revision with linear excision could increase the length of the scars and that muscle movement may cause the scars to be hypertrophic $[6,10,11]$. Autologous fat grafting is a treatment option, but the results can be unsatisfactory because the graft survival rate ranges from only $40 \%$ to $80 \%$ [12]. Although new approaches to fat grafting have been developed to improve the survival rate, the collection of fat tissues is still complicated, a large amount of time is still required, and problems related to reabsorption remain [12]. To avoid the need for tissue transplantation from a donor site, a potential alternative in which biomaterials facilitate tissue regeneration in the defect area has been developed $[7,9,13]$. Among the materials used, the extracellular matrix has been proven to be useful as a scaffold for tissue reconstruction and volume replacement [7-9]. Therefore, the use of ADM is another option for treating external fixation scars, such as those en- 
countered in our case.

The use of a fat graft before surgery in our case might have improved the circulation around the scars [12]; however, it was not as effective as ADM insertion. This may be due to the different physical properties of fat and ADM. Considering the physical characteristics of the scaffolds used in tissue engineering, ADM presents higher tensile stress than other biological materials, including human fat $[14,15]$. This may have contributed to the stable reshaping of the pin-site scars when ADM was inserted in the depressed area and to the enhancement of the dermal layer, keeping the skin from returning to its original site.

Scar revision procedures have the potential to improve patients' quality of life by creating scars with better tissue quality that are cosmetically and functionally more acceptable. Although more cases and studies are needed, this case shows that scar revision with an $\mathrm{ADM}$ can be useful for dimpled scars such as pin-site scars.

\section{NOTES}

\section{Conflict of interest}

No potential conflict of interest relevant to this article was reported.

\section{Ethical approval}

The study was performed in accordance with the principles of the Declaration of Helsinki.

\section{Patient consent}

The patient provided written informed consent for the publication and the use of her images.

\section{ORCID}

Yu Jin Kim

Ji Hun Kim

Yun Sang Kim

Young Woo Cheon

https://orcid.org/0000-0003-1333-4977
https://orcid.org/0000-0002-1947-2476
https://orcid.org/0000-0001-5412-4322
https://orcid.org/0000-0003-2940-292X

\section{REFERENCES}

1. Kani KK, Porrino JA, Chew FS. External fixators: looking beyond the hardware maze. Skeletal Radiol 2020;49:359-74.
2. Karlen LK, Yinusa W, Yan LS, et al. Analysis of scar formation after lower limb lengthening: influence on cosmesis and patient satisfaction. J Pediatr Orthop 2004;24:706-10.

3. Thione A, Gandolfi E, Mortarino C. A simple and effective technique for improving the appearance of pin-site scars. Injury 2010;41:e15-6.

4. Saleh M, Howard AC. Improving the appearance of pin-site scars. J Bone Joint Surg Br 1994;76:906-8.

5. Oznur A, Kayikcioglu A. A simple technique for improving the appearance of pin-site scars. Plast Reconstr Surg 2002;110:710-1.

6. Goutos I, Yousif AH, Ogawa R. W-plasty in scar revision: geometrical considerations and suggestions for site-specific design modifications. Plast Reconstr Surg Glob Open 2019;7:e2179.

7. Fosnot J, Kovach SJ 3rd, Serletti JM. Acellular dermal matrix: general principles for the plastic surgeon. Aesthet Surg J 2011;31(7 Suppl):5S$12 \mathrm{~S}$.

8. Costantino PD, Govindaraj S, Hiltzik DH, et al. Acellular dermis for facial soft tissue augmentation: preliminary report. Arch Facial Plast Surg 2001;3:38-43.

9. Sclafani AP, Romo T 3rd, Jacono AA, et al. Evaluation of acellular dermal graft in sheet (AlloDerm) and injectable (micronized AlloDerm) forms for soft tissue augmentation: clinical observations and histological analysis. Arch Facial Plast Surg 2000;2:130-6.

10. O'Kane S. Wound remodelling and scarring. J Wound Care 2002;11:296-9.

11. Garg S, Dahiya N, Gupta S. Surgical scar revision: an overview. J Cutan Aesthet Surg 2014;7:3-13

12. Kim JB, Jin HB, Son JH, et al. For better fat graft outcome in soft tissue augmentation: systematic review and meta-analysis. Arch Aesthetic Plast Surg 2018;24:116-27.

13. Jeong SH, Fan Y, Cheon $\mathrm{KH}$, et al. Hyaluronic acid-hydroxyapatite nanocomposite hydrogels for enhanced biophysical and biological performance in a dermal matrix. J Biomed Mater Res A 2017;105:331525.

14. Alkhouli N, Mansfield J, Green E, et al. The mechanical properties of human adipose tissues and their relationships to the structure and composition of the extracellular matrix. Am J Physiol Endocrinol Metab 2013;305:E1427-35.

15. Qiu YL, Chen X, Hou YL, et al. Characterization of different biodegradable scaffolds in tissue engineering. Mol Med Rep 2019;19:404356. 